\title{
Intestinal inflammatory and redox responses to the perioperative administration of teduglutide in rats ${ }^{1}$
}

Beatriz Pinto da Costa', Ana Cristina Gonçalves", Ana Margarida Abrantes"II, Paulo Matafome ${ }^{\text {IV }}$, Raquel Seiçav , Ana Bela Sarmento-RibeirovI, Maria Filomena BotelhovII, Francisco Castro-SousavilI

'MD, Department of Surgery “A", Hospitais da Universidade de Coimbra, Centro Hospitalar e Universitário de Coimbra, Portugal. Conception and design of the study; acquisition, analysis and interpretation of data; manuscript writing. "BSc, PhD, Laboratory of Oncobiology and Hematology, University Clinic of Hematology and Applied Molecular Biology Unit, Faculty of Medicine, Universidade de Coimbra, Portugal. Acquisition of data.

"'BSc, PhD, Center for Neuroscience and Cell Biology (CNC), and Institute for Biomedical Imaging and Life Sciences (IBILI), Faculty of Medicine, Universidade de Coimbra, Portugal. Acquisition of data.

IVBSc, PhD, Institute of Physiology, Faculty of Medicine, Universidade de Coimbra, Portugal. Acquisition of data.

${ }^{\vee} \mathrm{MD}$, Institute of Physiology, Faculty of Medicine, Universidade de Coimbra, Portugal. Critical revision.

${ }^{V} \mathrm{PhD}$, Center of Investigation in Environment, Genetics and Oncobiology (CIMAGO), Faculty of Medicine, Universidade de Coimbra, Portugal. Critical revision.

VIIPhD, Center for Neuroscience and Cell Biology (CNC) and Institute for Biomedical Imaging and Life Sciences (IBILI), Faculty of Medicine, Universidade de Coimbra, Portugal. Critical revision.

VIIIPhD, Department of Surgery "A", Hospitais da Universidade de Coimbra, Centro Hospitalar e Universitário de Coimbra, Portugal. Critical revision.

\section{Abstract}

Purpose: To investigate the inflammatory and redox responses to teduglutide on an animal model of laparotomy and intestinal anastomosis.

Methods: Wistar rats ( $n=62)$ were allocated into four groups: "Ileal Resection and Anastomosis" vs. "Laparotomy", each one split into "Postoperative Teduglutide Administration" vs. "No Treatment"; and euthanized at the third or the seventh day. Ileal and blood samples were recovered at the baseline and at the euthanasia. Flow cytometry was used to study the inflammatory response (IL-1 $\alpha$, MCP-1, TNF- $\alpha$, IFN- $\gamma$ and IL-4 levels), oxidative stress (cytosolic peroxides, mitochondrial reactive species, intracellular glutathione and mitochondrial membrane potential) and cellular viability and death (annexin V/propidium iodide double staining).

Results: Postoperative teduglutide treatment was associated with higher cellular viability index and lower early apoptosis ratio at the seventh day; higher cytosolic peroxides level at the third day and mitochondrial overgeneration of reactive species at the seventh day; higher tissue concentration of IL-4 and lower local pro-to-anti-inflammatory cytokines ratio at the seventh day.

Conclusion: Those findings suggest an intestinal pro-oxidative and anti-inflammatory influence of teduglutide on the peri-operative context with a potential interference in the intestinal anastomotic healing.

Key words: Glucagon-like peptide-2. Anastomosis, surgical. Cytokines. Oxidative Stress. 


\section{Introduction}

Glucagon-like peptide 2 (GLP-2) is a gastrointestinal growth factor, synthetized in enteroendocrine $L$ cells, that exerts a relevant role on the control of energy absorption and the preservation of intestinal mucosa morphology and function ${ }^{1}$. Teduglutide is a long-acting dipeptidylpeptidase IV-resistant equivalent of GLP-2 currently accepted for pharmacological rehabilitation of patients with short-bowel syndrome associated intestinal failure $^{2}$ and also considered a promising medication for moderate-to-severe Crohn's disease ${ }^{3}$. Several studies have demonstrated that, in patients with short-bowel syndrome, teduglutide treatment is safe, well tolerated and efficacious, with improvement of intestinal absorption and reduction of parenteral support requirements ${ }^{4,5}$. Teduglutide was recently approved by the European Medicines Agency for treatment of patients with shortbowel syndrome related parenteral support dependence despite optimized medical and dietetic treatment, aged more than one year and who are stable following a period of postsurgical intestinal adaptation ${ }^{6,7}$. Furthermore, in the recently published guidelines of the European Society for Clinical Nutrition and Metabolism, teduglutide was considered the first choice for carefully selected patients with chronic intestinal failure who are candidates for growth factor treatment ${ }^{8}$.

Several experimental studies, analyzing intestinal anastomotic repair-promoting methods, have suggested potential benefits from growth factors administration, including from insulin-like growth factor 1 , epidermal growth factor, heparin-binding epidermal growth factor and fibroblast growth factor-7/ keratinocyte growth factor ${ }^{9,10}$, which have been considered mediators of the GLP-2 effects ${ }^{1}$. In fact, a recently published study demonstrated, through histological and immunohistochemical analysis, a positive impact of teduglutide administration on the reepithelialization and neoangiogenesis events of the proliferative phase of the intestinal anastomotic repair on an experimental model ${ }^{11}$.

Intestinal inflammatory and redox responses to the perioperative administration of teduglutide are not yet well understood. It may be hypothesized that teduglutide influences inflammatory and redox reactions with a potential interference in the intestinal anastomotic healing. Knowledge of the potential influence of teduglutide on the intestinal anastomotic repair is relevant, not only for patients with short-bowel syndrome undergoing intestinal anastomosis (including autologous intestinal reconstruction procedures) during treatment with this growth factor, but also to explore its potential role as a perioperative adjuvant strategy.

Present study intends to investigate the inflammatory and redox responses to teduglutide short-term perioperative treatment on an animal model of laparotomy and intestinal anastomosis.

\section{- Methods}

Experiment was ratified by the Ethics Committee of the Faculty of Medicine, University of Coimbra, Coimbra, Portugal (Official Letter no32-06-2009) and implemented in consonance with the national recommendations for animals' safety.

Adult male Wistar albinus rats, weighting 250 to $300 \mathrm{~g}$, were randomly allocated into four groups: "Ileal Resection and Anastomosis" ("Res") versus "Laparotomy" ("Lap"), each one split into "Postoperative Teduglutide Administration" ("Ted + ") versus "No Treatment" ("Ted -"). Evaluation was accomplished at the operation and euthanasia, at the third or the seventh postoperative day (presumptively consonant with the 
inflammatory and proliferative stages of the intestinal anastomotic repair $\left.^{9,12}\right)$, with ileal harvesting and blood collection. Blinded assessment was guaranteed in all the laboratorial analysis.

All the operative interventions were executed by the same surgeon, after two hours solid fasting, with clean surgical technique and under anaesthesia with an intraperitoneal injection of ketamine hydrochloride $(75 \mathrm{mg} / \mathrm{kg}$; Pfizer Inc., NY, USA) and chlorpromazine (3 mg/ kg; Laboratórios Vitória, Amadora, Portugal).

In "Res" groups, a $10 \mathrm{~cm}$ length ileal resection was completed, retaining distal $5 \mathrm{~cm}$, through a $3 \mathrm{~cm}$ midline laparotomy, concluded with an end-to-end anastomosis with eight equidistant full-thickness polydioxanone USP 6/0 stitches (PDS II, Ethicon, Johnson-Johnson Intl); abdominal wall was closed with muscleaponeurotic and cutaneous continuous sutures of braided coated polyglactin 910 USP 4/0 (Surgilactin, Sutures Limited, UK) and natural silk USP 4/0 (Surgisilk, Sutures Limited, UK), respectively. In "Lap" groups, a $3 \mathrm{~cm}$ midline laparotomy was carried out with mild handling of the small bowel.

In the first postoperative day, 5\% glucose in water at a 1:1 ratio was provided and, then, ad libitum rodent diet and hydration were restored. At the third or seventh postoperative day, animals were euthanized by cervical displacement and a re-laparotomy with ileal resection was undertaken $(10 \mathrm{~cm}$ length, conserving distal $3 \mathrm{~cm}$ ).

In "Ted + " groups, teduglutide (American Peptide Company) was applied subcutaneously in the postoperative period (including on the day of the operation), 200 $\mu \mathrm{g} / \mathrm{kg} /$ day, after preparation in agreement with the manufacturer's recommendations. Administration schedule of teduglutide was based on precedent experimental and clinical studies on the intestinotrophic and pharmacodynamic attributes of GLP-2 and its analogues ${ }^{2,13-16 .}$

\section{Tissue and blood sampling}

Three similar longitudinal strips of the most distal $4 \mathrm{~cm}$ length of each ileal specimen, each one corresponding to one third of the circumference, were carefully retrieved for cell isolation procedure, homogenization and $10 \%$ formaldehyde fixation, respectively. In "Res" groups, tissue samples obtained at euthanasia corresponded to the anastomotic segment and included the anastomosis in the middle. Tissue baseline values of "Res" groups were considered for comparison with postoperative results of the "Lap" groups.

Blood samples of $1 \mathrm{ml}$ were collected before the operations, into EDTA-containing tubes, stabilized with $0.1 \mathrm{mg} / \mathrm{ml}$ of aprotinin from bovine lung (Sigma-Aldrich) and 0.037 $\mathrm{mg} / \mathrm{ml}$ of nicotinonitrile dihydrochloride hydrate (Sigma Aldrich) and centrifuged for 20 minutes at $1500 \times \mathrm{g}$ and $4^{\circ} \mathrm{C}$. Plasma aliquots were maintained at $-80^{\circ} \mathrm{C}$.

Tissue dissociation and cell isolation procedure

Cells were isolated from one ileal longitudinal strip by a modified collagenase/ dispase isolation protocol ${ }^{17,18}$ to obtain preparations predominantly constituted of epithelial cells and some stromal cells.

\section{Tissue homogenization}

Fragments from one ileal longitudinal strip, with approximately $1 \mathrm{~mm}$, were rapidly introduced in a mixture of protease inhibitors (1 $\mathrm{ml} / 100 \mathrm{mg}$ ) and submitted to mechanical homogenization. Inhibitors cocktail was previously prepared by adding aprotinin from bovine lung (Sigma Aldrich), leucopeptin hemisulfate salt (Sigma Aldrich) and pepstatin A (Sigma Aldrich) ( $1 \mu \mathrm{l}$ of each, all diluted in a $10 \mathrm{mg} / \mathrm{ml}$ stock concentration) to $10 \mathrm{ml}$ of 
phosphate buffered saline (PBS, pH 7.4, Gibco, LifeTechnologies). Preparation was sonicated twice with one short pulse of ten seconds, cooled during ten seconds and distributed into two tubes of $1.5 \mathrm{ml}$. Sonication (one pulse of ten seconds) was repeated and centrifugation was undertaken, 14000x $\mathrm{g}$, for ten minutes, at $4^{\circ} \mathrm{C}$. Supernatant was removed to a new tube. Centrifugation was repeated twice and supernatant was removed, aliquoted (100 $\mu \mathrm{l})$ and stored at $-80^{\circ} \mathrm{C}$ until further use.

\section{Cellular viability and death study}

Annexin V/propidium iodide double staining was used to evaluate viability and death in isolated cells, with the Annexin V-FITC Apoptosis Detection Kit (Immunostep, Salamanca, Spain) according previously described methods ${ }^{19}$. Analysis was accomplished using a FACSCalibur flow cytometer (Becton Dickinson, San Jose, CA, USA). Cells were defined according the positivity for annexin $\mathrm{V}(\mathrm{AV})$ and/or propidium iodide (PI) labelling. Results were presented as percentage of early apoptotic ( $\mathrm{AV}+\mathrm{PI}-)$, late apoptotic/necrotic $(\mathrm{AV}+/ \mathrm{PI}+)$, necrotic $(\mathrm{AV}-/$ $\mathrm{PI}+$ ) and viable cells (AV-/PI-).

\section{Oxidative stress evaluation}

Subsequent parameters were
analysed in isolated cells by flow cytometry: peroxides levels in cytosol, with 2',7'-dichlorodihydrofluorescein diacetate $\left(\mathrm{DCFH}_{2}\right.$-DA) probe (Molecular Probes, Invitrogen); reactive species production in mitochondria, with dihydrorhodamine 123 (DHR 123) probe (Molecular Probes; Invitrogen); intracellular reduced glutathione (GSH) content, with mercury orange staining (Sigma-Aldrich); and mitochondrial membrane potential, with 5,5',6,6'-tethrachloro-1,1',3,3'tethraethylbenzimidazolcarbocyanine iodide probe (JC-1; Molecular Probes, Invitrogen).
Analysis was fulfilled using the flow cytometer and software outlined above, conforming to formerly detailed techniques ${ }^{19,20}$. Results were revealed as mean fluorescence intensity (MFI) values. Experiments were carried out in duplicate.

\section{Analysis of tissue and systemic inflammatory response}

A multiplex cytokine bead array approach was used to measure the expression of inflammatory cytokines, using the Rat Cytokine 5plex Kit FlowCytomix (Affymetrix eBioscience) produced for quantification of rat's homogenized tissue and plasma levels of interleukine-1 $\alpha$ (IL-1 $\alpha)$, macrophage chemo-attractant protein (MCP-1), tumour necrosis factor- $\alpha$ (TNF- $\alpha$ ), interferon- $\gamma$ (IFN- $-\gamma$ ) and interleukine-4 (IL-4). Standard and test samples were analysed using a FACSCalibur flow cytometer as stated in the manufacturer's instructions. All the samples were run in duplicate. Tissue concentrations were normalized to the total protein content of the sample, estimated by the bicinchoninic acid protein assay $^{21}$ using bovine serum albumin as standard, and expressed as pg/ $\mathrm{pg}$ protein. Pro-to-anti-inflammatory cytokines ratio ([IL$1 \alpha]+[$ TNF- $\alpha]+[I F N-\gamma] /[I L-4])$ and Helper cell type 1 lymphocytes (Th1)-to-helper cell type 2 lymphocytes (Th2) cytokines quotient ([TNF$\alpha]+[$ IFN- $\gamma] /[\mathrm{IL}-4])$ were calculated ${ }^{22,23}$.

\section{Statistical analysis}

Statistical analysis was completed using the SPSS Software version 18.0 (SPSS, Chicago, IL, USA). Testing for normality was performed with Shapiro Wilk and KolmogorovSmirnov-Lillifors tests. Data were indicated as median and interquartile range (median \pm IQR). Non-parametric continuous variables were compared by Mann-Whitney $U$ test and analysis of variance by ranks (Kruskall-Wallis 
test) with pairwise comparisons; correlations were determined by the Spearman's rank correlation coefficient $(\sigma)$. Differences were considered statistically significant at a level of $95 \%(p<0.05)$.

\section{- Results}

Sixty-two animals were recruited and 59 completed the study. They were distributed in the following groups: "Res Ted -" ( $n=13$, eight euthanized at the seventh day), "Res Ted + " $(n=15$, seven euthanized at the seventh day), "Lap Ted -" ( $n=15$, eight euthanized at the seventh day) and "Lap Ted + " ( $n=16$, eight euthanized at the seventh day). There were two cases of mortality associated with anastomotic dehiscence (in "Res Ted -" and "Res Ted +" groups, respectively) and one of indeterminate etiology (in "Res Ted -" group), that were rejected from further analysis. In the remaining animals, there was no evidence of anastomotic fistulae, intra-abdominal abscess or peritonitis.

\section{Cellular viability and death}

In animals not submitted to teduglutide treatment, ileal peri-anastomotic segments demonstrated a significant decrease of viable cells proportion between the third and seventh days ( $p=0.01$ ) (Figure 1a).

Teduglutide administration was associated with an increase of viability index in the cells isolated from the peri-anastomotic segment at the seventh day $(p=0.005)$ (Figure 1b). Global evaluation of the effects of postoperative teduglutide treatment underscored the increase of cellular viability $(p=0.0001)$ and decrease of early apoptosis occurrences at the seventh day $(p=0.001)$ (Figure 1c).
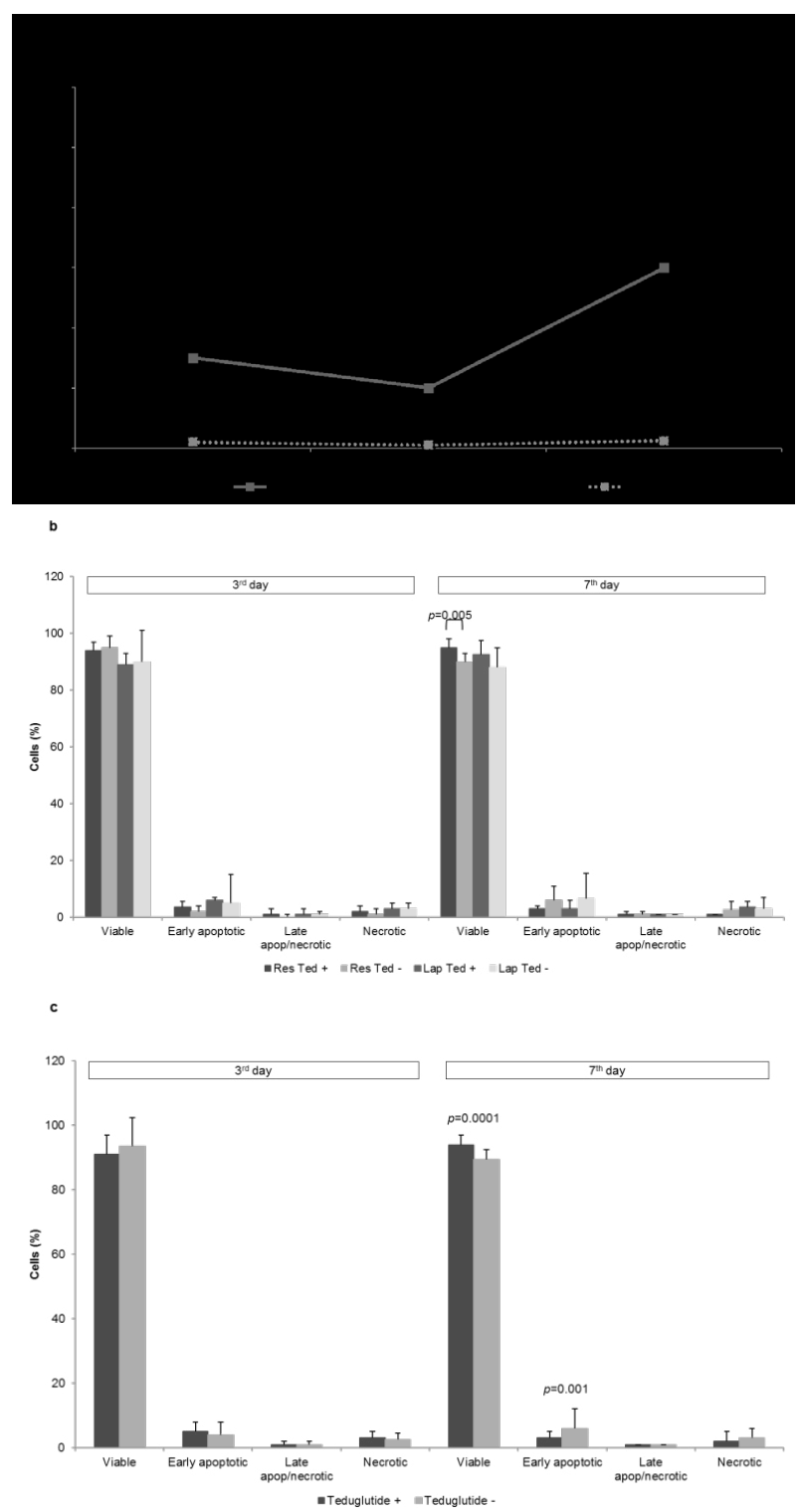

Figure 1 - Analysis of viability and death in cells isolated from rats' ileum, by flow cytometry using double staining with Annexin V/Propidium iodide: at the third and seventh days after ileal resection and anastomosis in animals not submitted to teduglutide treatment (a), in the different groups of study (b) and according teduglutide administration (c).

Animals $(n=59)$ were submitted to ileal resection and anastomosis (Res) or 
laparotomy (Lap) and euthanized at the third or at the seventh postoperative days. In groups "Res Ted +" and "Lap Ted +", teduglutide was administered after the operation. Samples recovered at euthanasia from rats submitted to ileal resection corresponded to the anastomotic segment. Baseline values of rats that undergo ileal resection were considered for comparison. Data were explicited as percentage (\%) of viable, early apoptotic, late apoptotic/necrotic (late apop/necrotic) and necrotic cells (median \pm IQR). Kruskal-Wallis test with pairwise comparison and Mann-Whitney $U$ test were used.

\section{Oxidative stress}

Intestinal anastomotic healing induced a pro-oxidative influence, particularly evident at the third day, that was expressed by an increase of cytosolic peroxides level $(p=0.0001)$ and reactive species generation in the mitochondria $(p=0.005)$ and by a reduction of mitochondrial membrane potential $(p=0.001)$ and cellular reduced glutathione content $(p=0.001)$ until the seventh day (Figure 2a).

Teduglutide treatment appeared to reinforce the pro-oxidative effects of anastomotic repair, although without reaching statistical significance (Figure $2 b$ ). When considering all the operated animals postoperative teduglutide administration was significantly associated with an increase of the cytosolic peroxides level at the third day $(p=0.042)$, as well as of the mitochondrial generation of reactive species at the seventh day $(p=0.0011$ ) (Figure $2 c)$.
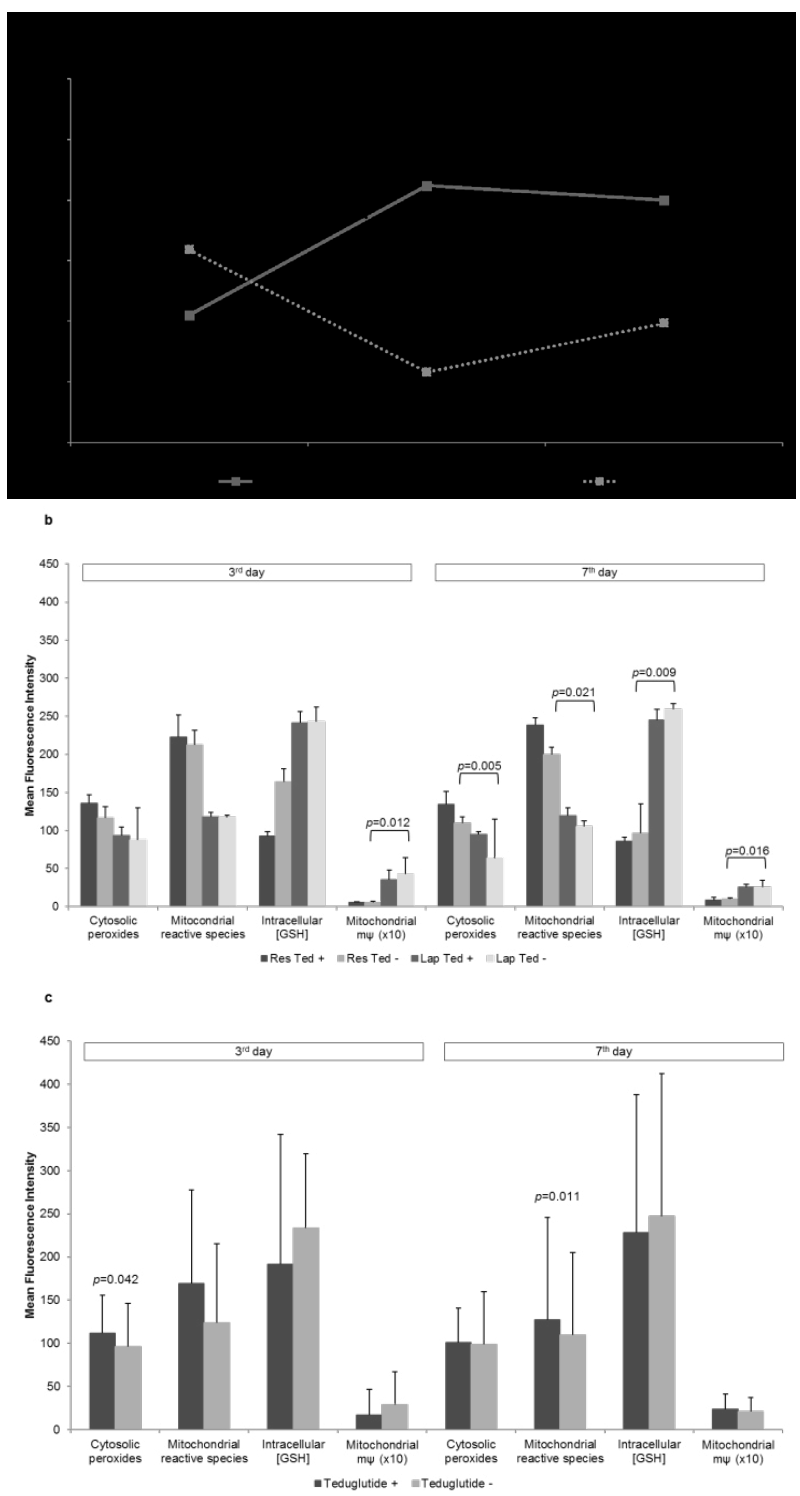

Figure 2 - Oxidative stress evaluation in cells isolated from rats' ileum: at the third and seventh days after ileal resection and anastomosis in animals not submitted to teduglutide treatment (a), in the different groups of study (b) and according teduglutide administration (c). Assessment was performed by flow cytometry using DCFH2DA, DHR123 and JC-1 fluorescent probes and mercury orange to determine cytosolic peroxides level, mitochondrial reactive species generation, mitochondrial membrane potential $(\mathrm{m} \psi)$ and cellular reduced glutathione content ([GSH]), respectively. 
Animals ( $n=59)$ were submitted to ileal resection and anastomosis (Res) or laparotomy (Lap) and euthanized at the third or at the seventh postoperative days. In groups "Res Ted +" and "Lap Ted +", teduglutide was administered after the operation. Samples recovered at euthanasia from rats submitted to ileal resection corresponded to the anastomotic segment. Baseline values of rats that undergo ileal resection were considered for comparison. Data were presented as mean fluorescence intensity (MFI) values (median \pm IQR). Results of JC-1 probe were expressed as aggregates/ monomers ratio. Kruskal-Wallis test with pairwise comparison and Mann-Whitney $U$ test were used.

\section{Local inflammatory response}

Anastomotic repair induced a significant upregulation of tissue IL-1 $\alpha(p=0.0001)$, MCP-1 $(p=0.026)$ and TNF- $\alpha(p=0.0001)$ until the third day, with a drop of TNF- $\alpha$ thereafter; as well as of IFN- $\gamma$ between the third and seventh days $(p=0.034)$ (Figure 3a). An increase of pro-to-anti-inflammatory cytokines ratio until the seventh day $(623.8 \pm 422.5$ versus 7098.5 $\pm 7396.5, p=0.0001)$ and of Th1-to-Th2 cytokines ratio, especially until the third day $(0.0 \pm 0.9$ versus $118.2 \pm 49.3, p=0.0001)$ was observed in the peri-anastomotic segment.

Teduglutide administration was associated with higher tissue levels of IL-4 at the seventh day after isolated laparotomy $(p=0.036)$ (Figure 3b). Teduglutide treatment was associated with a higher expression of IL-4 at the seventh day after the operation $(p=0.0001)$ (Figure $3 c)$, concomitant with a lower pro-to-anti-inflammatory and Th1-toTh2 cytokines ratios $(409.3 \pm 1768.1$ versus $2864.5 \pm 6613.6, p=0.012$ and $0.0 \pm 2.2$ versus $3.0 \pm 7.3, p=0.017$, respectively).
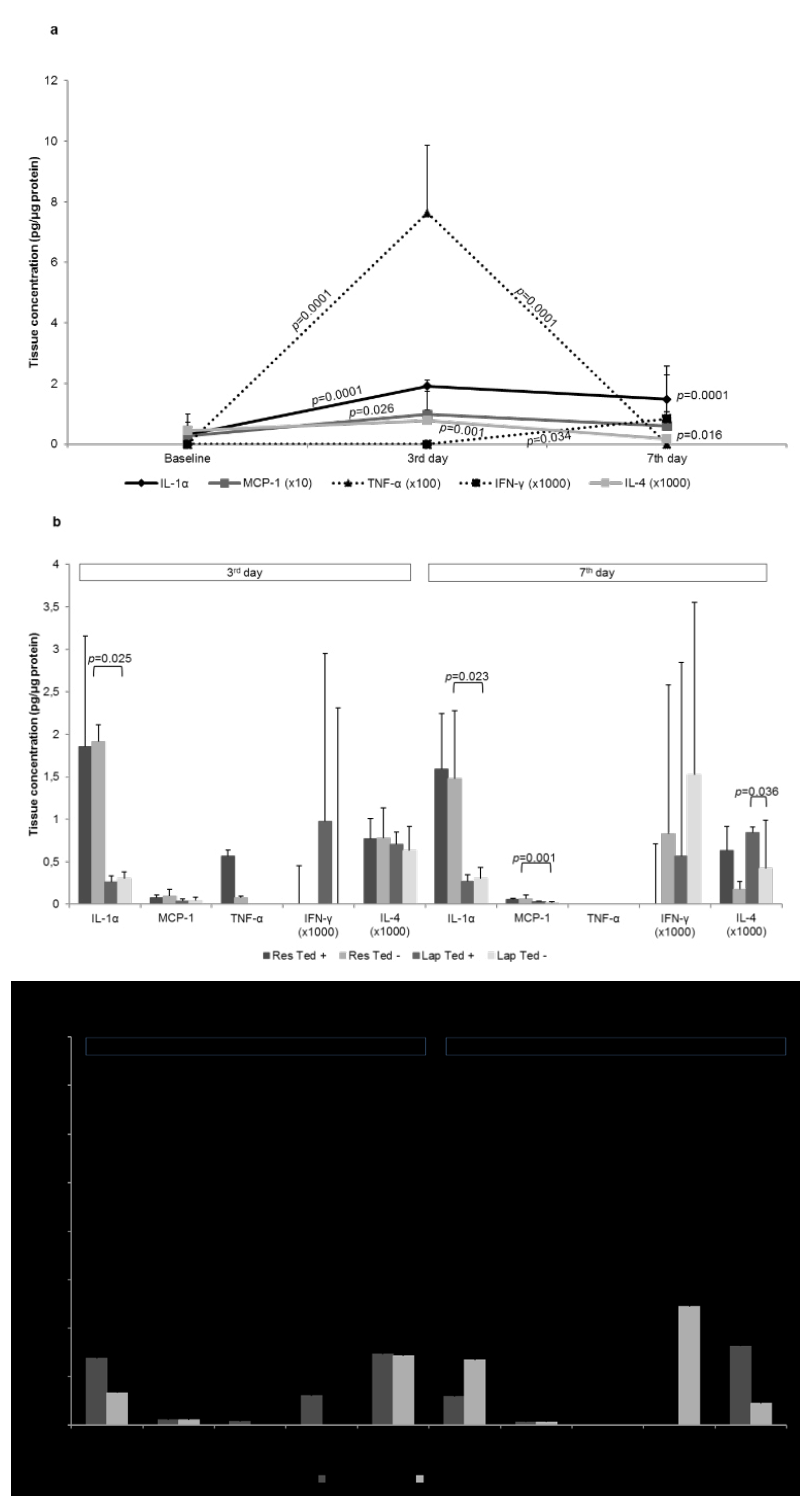

Figure 3 - Analysis of tissue inflammatory response in rats' ileum by flow cytometric multiplexed bead assay: at the third and seventh days after ileal resection and anastomosis in animals not submitted to teduglutide treatment (a), in the different groups of study (b) and according teduglutide administration (c).

Animals $(n=59)$ were submitted to ileal resection and anastomosis (Res) or laparotomy (Lap) and euthanized at the third or at the seventh postoperative days. In groups "Res Ted +" and "Lap Ted +", teduglutide was administered after the operation. Samples recovered at euthanasia from rats submitted to ileal resection corresponded to the anastomotic 
segment. Cytokines concentrations were determined as function of fluorescence intensities and normalized to the protein content of the sample. Baseline values of rats that undergo ileal resection were considered for comparison. Data were expressed as pg/ mg (median $\pm \mid Q R$ ). Kruskal-Wallis test with pairwise comparison and Mann-Whitney $U$ test were used.

\section{Systemic inflammatory response}

After ileal resection and anastomosis, an increase of plasma IFN- $\gamma$ levels until the third day $(287.8 \pm 99.5$ versus $605.5 \pm 61.8 \mathrm{pg} /$ $\mathrm{ml}, p=0.001$, respectively) was documented; on the other hand, a decrease of IL-1 $\alpha$ and TNF- $\alpha$ concentrations until the seventh day $(p=0.0001$ and $p=0.0001$, respectively) was also observed (Figure 4a).

Plasma pro-to-anti-inflammatory and Th1-to-Th2 cytokines ratios increased until the third day after ileal resection and anastomosis (32.7 \pm 11.7 versus $47.3 \pm 12.3, p=0.017$ and $16.2 \pm 6.1$ versus $23.1 \pm 8.2$, n.s., respectively) and decreased thereafter $(47.3 \pm 12.3$ versus $8.2 \pm 2.3, p=0.0001$ and $23.1 \pm 8.2$ versus $8.2 \pm 2.3$, $p=0.0001$, respectively).

Teduglutide administration was associated with lower plasma levels of IL$1 \alpha$, IFN- $\gamma$ and TNF- $\alpha$ at the seventh day after laparotomy ( $p=0.0001$, respectively); lower levels of IL-4 at both moments of evaluation after laparotomy $(p=0.013$ and $p=0.0001$, respectively); as well as lower plasma concentrations of IFN $-\gamma$ at the third day after ileal resection and anastomosis $(p=0.004)$ (Figure $4 \mathrm{~b}$ ). When analyzing all the animals, teduglutide administration was associated with lower plasma levels of IFN- $\gamma$ at the third day $(p=0.026)$ and of IL-1 $\alpha \quad(p=0.004)$, TNF- $\alpha(p=0.002), \quad$ IFN- $\gamma \quad(p=0.0001)$ and IL-4 $(p=0.0001)$ at the seventh day (Figure 4c). That growth factor was not associated with significant modifications of plasma pro-to-antiinflammatory or Th1-to-Th2 cytokine ratios.
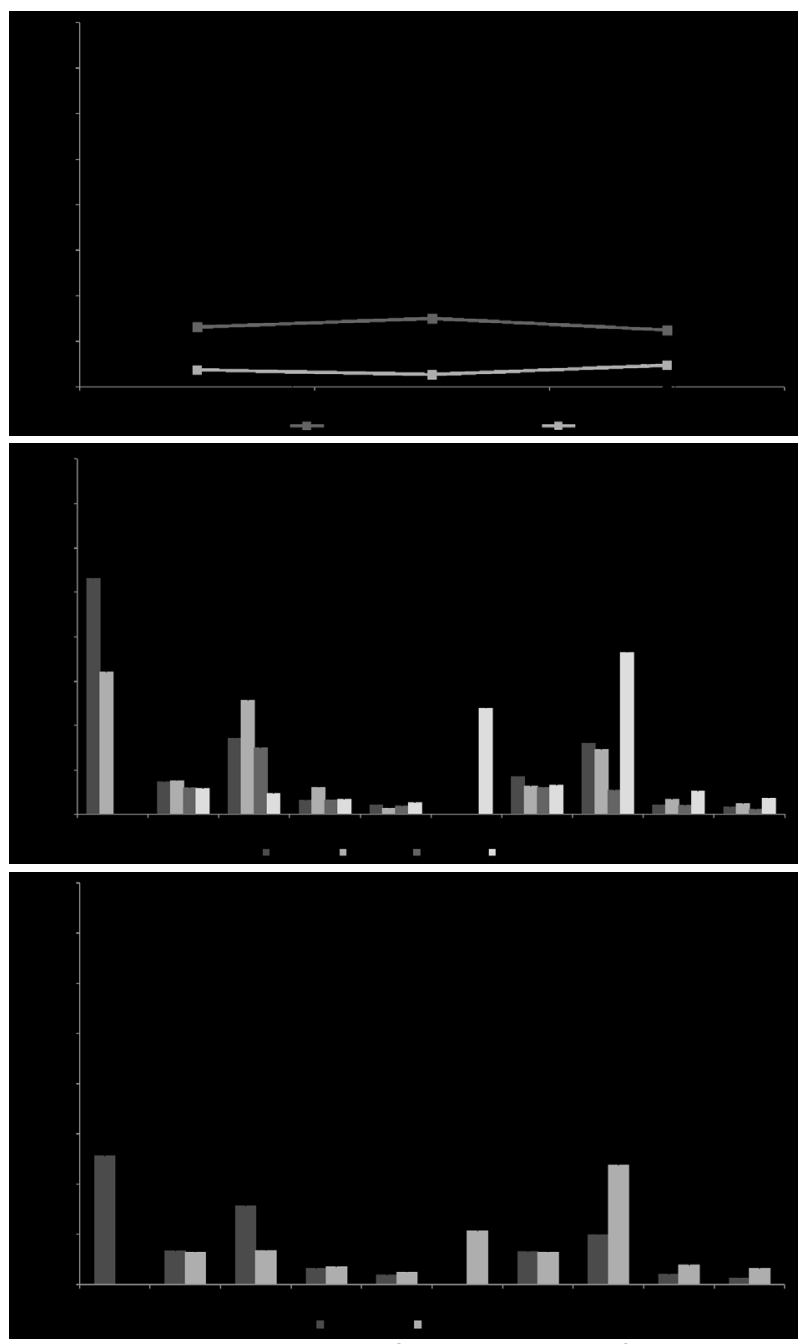

Figure 4 - Analysis of systemic inflammatory response by flow cytometric multiplexed bead assay: at the third and seventh days after ileal resection and anastomosis in animals not submitted to teduglutide treatment (a), in the different groups of study (b) and according teduglutide administration (c).

Animals $(n=59)$ were submitted to ileal resection and anastomosis (Res) or laparotomy (Lap) and euthanized at the third or at the seventh postoperative days. In groups "Res Tedt" and "Lap Ted+", teduglutide was administered after the operation. Baseline values were considered for comparison. Data were transmited as plasma concentration (pg/ $\mathrm{ml}$ ) (median \pm IQR). Kruskal-Wallis test with pairwise comparison and Mann-Whitney $U$ test were used. 
Relevant correlations between cellular viability and death indexes, oxidative stress parameters and cytokines levels at the euthanasia

In the postoperative evaluation of cells isolated from the rats' ileum, cytosolic peroxides level, mitochondrial reactive species generation and mitochondrial membrane potential levels correlated moderately and significantly with cellular viability $(\sigma=50.4 \%$, $p=0.0001 ; \sigma=61.9 \%, p=0.0001$ and $\sigma=-49.8 \%$, $p=0.0001$, respectively) (Table 1 ).

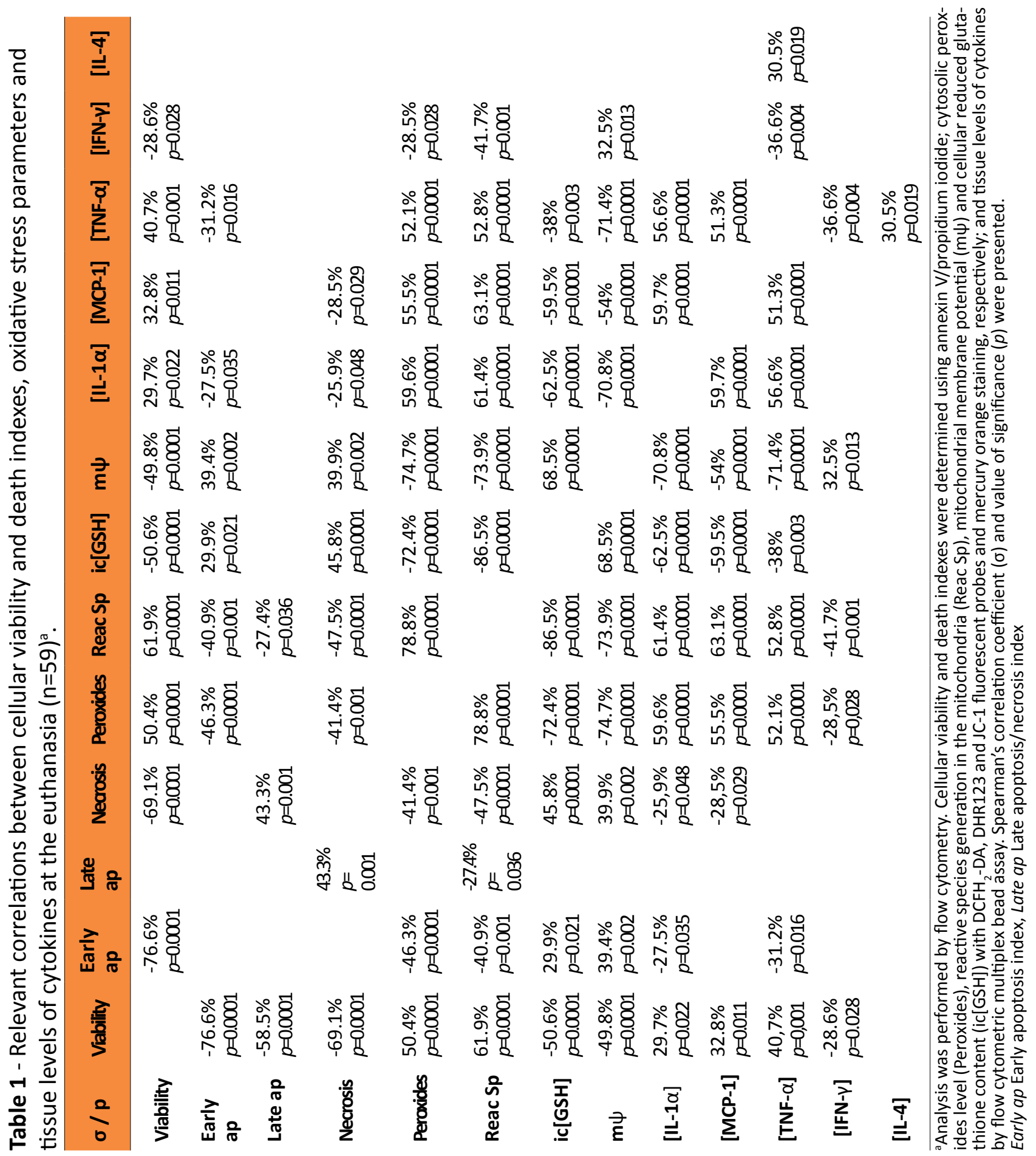




\section{- Discussion}

Intestinal anastomotic healing is a complex process that progresses in three coinciding steps: inflammatory, proliferative and remodeling ${ }^{9,12}$. In this study, the repair process induced a significant decrease in the percentage of viable cells isolated from the peri-anastomotic segment between both postoperative moments of evaluation. Intestinal anastomotic healing was characterized by a relevant and sustained pro-oxidative influence, particularly evident at the third day, including an increase of oxidative burden and a decrease of cellular mechanisms of protection against oxidative injury, as expected to occur during the infiltration of the wounded tissues by inflammatory cells ${ }^{9,24}$.

In the present study, anastomotic healing activated a predominant tissue proinflammatory and Th1 response. Repair process promoted a significant upregulation of IL- $1 \alpha$, MCP-1 and TNF- $\alpha$ until the third day; and of IFN- $\gamma$ between the third and the seventh days. Similarly, Seifert et al. ${ }^{25}$ demonstrated an upregulation of tissue IL-1 $\alpha$ and IL-1 $\beta$ gene expressions on the second day and a downregulation in the later course until the eighth day, although without a consistent regulation of IFN- $\gamma$ gene expression. Other authors described upregulation of IL-1 $\beta$ until the seventh day after an ileal anastomosis ${ }^{26,27}$ and increase of IFN- $\gamma$ expression between the third and seventh days ${ }^{27}$; however, contrary to the present findings, they observed a decrease of TNF- $\alpha$ levels at the third postoperative day $^{26,27}$. In this investigation, downregulation of IL-4 at the seventh postoperative day was concordant with the literature ${ }^{26}$ and the MCP-1 kinetic profile in the anastomotic segment was analogous to that previously demonstrated by Alzoghaibi et al. ${ }^{28}$.
Our results revealed a predominant pro-inflammatory and Th1 systemic response at the third day after intestinal resection and anastomosis and a prevailing anti-inflammatory and Th2 systemic reaction at the seventh day, in concordance with the literature ${ }^{29}$. As reported by previous experimental and clinical studies, the initial pro-inflammatory phase of the host response during the early postoperative period is followed by anti-inflammatory cytokines production by Th2 lymphocytes ${ }^{30}$. Surgical stress induces a shift in the Th1/Th2 cell balance towards Th2 $2^{22,29,31}$, suggesting downregulation of cell-mediated and upregulation of antibodymediated immunity, proportional to the magnitude of injury ${ }^{22,31}$.

This study demonstrated a favorable influence of teduglutide on intestinal cellular viabilityin theperioperative context, particularly after ileal resection and anastomosis, and confirms its anti-apoptotic effects. Previous studies demonstrated that GLP-2 increases intestinal epithelial proliferation in the crypts and inhibits apoptosis in the crypts and villi ${ }^{1}$.

Furthermore, present findings suggested a pro-oxidative influence of teduglutide and did not corroborate other authors' conclusions pointing to an antioxidative effect ${ }^{1,16,32}$. Dissimilar results may be explained be the use of different models of intestinal injury, materials for oxidative stress analysis and teduglutide administration schedules (timing and posology). In fact, Arda-Pirincci et al. $^{16}$ demonstrated that teduglutide pretreatment prevented tumor necrosis factor-alpha/actinomycin D-induced intestinal oxidative injury, in a mouse model, with reduction of lipid peroxidation (malondialdehyde levels) and glutathione levels, glutathione peroxidase and superoxide dismutase activities and a marked increase in catalase activity. 
In our investigation, postoperative prooxidative effect of teduglutide was expressed by an increase of peroxides level in the cytosol at the third day and of reactive species generation in the mitochondria at the seventh day. Those parameters of oxidative stress correlated positively with cellular viability index suggesting absence of deleterious effects on cellular death induction and, on the contrary, a favorable influence on viability; indeed, in present analysis, teduglutide was associated with pro-viability and anti-apoptotic effects. Although excessive intestinal oxidative stress may negatively influence anastomotic repair through disruption of cell signaling (including of redox modulation of effector cells proliferation and differentiation), irreversible oxidation of macromolecules and induction of cell death ${ }^{33,34}$, as demonstrated by other authors $^{35,36}$, a certain level of redox stimulus is necessary to the normal course of the wound healing process ${ }^{9,24,37}$.

In our experiment, teduglutide postoperative treatment was related with a significant upregulation of tissue IL-4 expression at the seventh postoperative day and a shift of the postoperative local balance towards an anti-inflammatory and Th2 response at that time point, although those effects did not reach statistical significance when analyzing exclusively the anastomotic segments. Present results suggest that teduglutide may influence anastomotic healing through the interference in the pro- and anti-inflammatory pathways, with a predominantly anti-inflammatory effect at the seventh postoperative day. Upregulation of IL-4 at the seventh day may promote the transition from a predominantly inflammatory state to a more proliferative phase of healing. IL-4 has been associated with activation and differentiation of fibroblasts, production of collagens, upregulation of matrix metalloproteinases "-2" and "-9" and tissue inhibitor of metalloproteinase-1, inhibition of the Th1 response and stimulation of Th2 cells ${ }^{24}$. GLP-2 has been considered to have an important anti-inflammatory activity, documented in animal models of chemically induced ileitis and colitis, promoting the reduction of local expression of IL-1 $\beta$, IFN- $\gamma$ and TNF- $\alpha$ and the increase of IL-10 and IL-4 levels ${ }^{38,39}$. The anti-inflammatory effects of GLP-2 were also recently demonstrated on an experimental rat model of necrotizing enterocolitis, with reduction of ileal interstitial TNF- $\alpha$ and IL- 6 levels and improvement of clinical sickness score and survival rate ${ }^{40}$.

\section{- Conclusions}

The intestinal anastomotic healing was characterized by a local pro-oxidative and pro-inflammatory response. Surgical injury associated with intestinal resection and anastomosis induced a systemic predominantly pro-inflammatory and Th1 cytokines reaction at the third day and an anti-inflammatory and Th2 response at the seventh day.

Postoperative teduglutide treatment was significantly associated with a tissue prooxidative and anti-inflammatory influence with a potential interference in the inflammatory and proliferative phases of the intestinal anastomotic healing.

\section{References}

1. Drucker DJ, Yusta B. Physiology and pharmacology of the enteroendocrine hormone glucagon-like peptide-2. Annu Rev Physiol. 2014;76:561-83. PMID: 24161075.

2. Burness CB, McCormack PL. Teduglutide: a review of its use in the treatment of patients with short bowel syndrome. Drugs. 2013;73:935-47. PMID: 23729002.

3. Blonski W, Buchner AM, Aberra F, Lichtenstein 
G. Teduglutide in Crohn's disease. Expert Opin Biol Ther. 2013;13:1207-14. PMID: 23834252.

4. Naberhuis JK, Tappenden KA. Teduglutide for safe reduction of parenteral nutrient and/or fluid requirements in adults: a systematic review. JPEN J Parenter Enteral Nutr. 2016;40:1096-105. PMID: 25883117.

5. Austin K, Markovic MA, Brubaker PL. Current and potential therapeutic targets of glucagon-like peptide-2. Curr Opin Pharmacol. 2016;1:13-18. PMID 27580097.

6. Kim ES, Keam SJ. Teduglutide: A Review in short bowel syndrome. Drugs. 2017;77:34552. PMID: 28194723.

7. Billiauws L, Bataille J, Boehm V, Corcos O, Joly F. Teduglutide for treatment of adult patients with short bowel syndrome. Expert Opin Biol Ther. 2017;17:623-32. PMID: 28293969.

8. Pironi L, Arends J, Bozzetti F, Cuerda C, Lyn Gillanders L, Jeppesen PB, Joly F, Kelly D, Lal S, Staun M, Szczepanek K, Van Gossum A, Wanten G, Schneider SM; Home Artificial Nutrition \& Chronic Intestinal Failure Special Interest Group of ESPEN. ESPEN guidelines on chronic intestinal failure in adults. Clin Nutr. 2016;35:247-307. PMID: 26944585.

9. Rijcken E, Sachs L, Fuchs T, Spiegel HU, Neumann PA. Growth factors and gastrointestinal anastomotic healing. J Surg Res. 2014;187:202-10. PMID: 24290527.

10. Øines MN, Krarup P, Jorgensen LN, Agren MS. Pharmacological interventions for improved colonic anastomotic healing: a meta-analysis. World J Gastroenterol. 2014;20:12637-48. PMID: 25253969.

11. Costa BP, Cipriano MA, Gonçalves AC, Abrantes AM, Matafome $P$, Seiça $R$, Sarmento-Ribeiro AB, Botelho MF, CastroSousa F. Effects of teduglutide on histological parameters of intestinal anastomotic healing. Eur Surg. 2017:1-10. doi: 10.1007/ s10353-017-0478-9.

12. Thompson SK, Chang EY, Jobe BA. Clinical review: healing in gastrointestinal anastomoses. Part I. Microsurgery. 2006;26:131-6. PMID: 16518804.

13. Martin GR, Wallace LE, Sigalet DL. Glucagonlike peptide- 2 induces intestinal adaptation in parenterally fed rats with short bowel syndrome. Am J Physiol Gastrointest Liver Physiol. 2004;286(6):G964-72. PMID: 14962847.

14. Kaji T, Tanaka $\mathrm{H}$, Holst JJ, Redstone $\mathrm{H}$, Wallace $L$, de Heuval E, Sigalet DL. The effects of variations in dose and method of administration on glucagon like peptide-2 activity in the rat. Eur J Pharmacol. 2008;596:138-45. PMID: 18762180.

15. Kaji T, Tanaka H, Redstone H, Wallace LE, Holst JJ, Sigalet DL. Temporal changes in the intestinal growth promoting effects of glucagon-like peptide 2 following intestinal resection. J Surg Res. 2009;152:271-80. PMID: 19062041.

16. Arda-Pirincci $P$, Bolkent $S$. The role of glucagon-like peptide-2 on apoptosis, cell proliferation, and oxidant-antioxidant system at a mouse model of intestinal injury induced by tumor necrosis factoralpha/actinomycin D. Mol Cell Biochem. 2011;350:13-27. PMID: 21153865.

17. Evans GS, Flint N, Somers AS, Eyden B, Potten CS. The development of a method for the preparation of rat intestinal epithelial cell primary cultures. J Cell Sci. 1992;101:21931. PMID: 1569126.

18. Dekaney CM, Fong JJ, Rigby RJ, Lund PK, Henning SJ, Helmrath MA. Expansion of intestinal stem cells associated with long-term adaptation following ileocecal resection in mice. Am J Physiol Gastrointest Liver Physiol. 2007;293:G1013-22. PMID: 17855764.

19. Gonçalves AC, Alves V, Silva T, Carvalho C, Oliveira CR, Sarmento-Ribeiro AB. Oxidative stress mediates apoptotic effects of ascorbate and dehydroascorbate in human myelodysplasia cells in vitro. Toxicol In Vitro. 2013;27:1542-9. PMID: 23542209.

20. Almeida $S$, Sarmento-Ribeiro $A B$, Januário C, Rego AC, Oliveira CR. Evidence of apoptosis and mitochondrial abnormalities in peripheral blood cells of Huntington's disease patients. Biochem Biophys Res Commun. 2008;374:599-603. PMID: 18625199.

21. Smith PK, Krohn RI, Hermanson GT, Mallia AK, Gartner FH, Provenzano MD, 
Fujimoto EK, Goeke NM, Olson BJ, Klenk DC. Measurement of protein using bicinchoninic acid. Anal Biochem. 1985;150:76-85. PMID: 3843705.

22. Ramírez MF, Huitink JM, Cata JP. Perioperative clinical interventions that modify the immune response in cancer patients. Open J Anesthesiol. 2013;3:133-9. doi: 10.4236/ojanes.2013.33031.

23. Menger MD, Vollmar B. Surgical trauma: hyperinflammation versus immunosuppression? Langenbecks Arch Surg. 2004;389:475-84. PMID: 15173946.

24. Speca S, Giusti I, Rieder F, Latella G. Cellular and molecular mechanisms of intestinal fibrosis. World J Gastroenterol. 2012;18:3635-61. PMID: 22851857.

25. Seifert GS, Seifert M, Kulemann B, Holzner PA, Glatz T, Timme S, Sick O, Höppner J, Hopt UT, Marjanovic G. Searching for the molecular benchmark of physiological intestinal anastomotic healing in rats: an experimental study. Eur Surg Res. 2014;53:73-85. PMID: 25139553.

26. Zubaidi A, Buie WD, Hart DA, Sigalet D. Temporal expression of cytokines in rat cutaneous, fascial and intestinal wounds: a comparative study. Dig Dis Sci. 2010;55:1581-8. PMID: 19697130.

27. Zubaidi AM, Hussain T, Alzoghaibi MA. The time course of cytokine expressions plays a determining role in faster healing of intestinal and colonic anastomotic wounds. Saudi J Gastroenterol. 2015;21:412-7. PMID: 26655138.

28. Alzoghaibi MA, Zubaidi AM. Upregulation of the proinflammatory cytokine-induced neutrophil chemoattractant-1 and monocyte chemoattractant protein-1 in rats' intestinal anastomotic wound healing does it matter? Asian J Surg. 2014;37:86-92. PMID: 24060212.

29. Murakami M, Sato $N$, Sato N, Nakamura $\mathrm{T}$, Masunaga $\mathrm{H}$. Changes in lymphocyte phenotypes and cytokine production by surgical stress in a rat small intestinal resection model. J Clin Biochem Nutr. 2007;40:216-20. PMID: 18398499.

30. Choileain N, Redmond HP. Cell response to surgery. Arch Surg. 2006;141:1132-40. PMID: 17116807.
31. Decker $D$, Schondorf $M$, Bidlingmaier $F$, Hirner A, von Ruecker AA. Surgical stress induces a shift in the type-1/type-2 T-helper cell balance, suggesting down-regulation of cell-mediated and up-regulation of antibodymediated immunity commensurate to the trauma. Surgery. 1996;119:316-25. PMID: 8619187.

32. Janssen $P$, Rotondo A, Mulé F, Tack J. Review article: a comparison of glucagonlike peptides 1 and 2. Aliment Pharmacol Ther. 2013;37:18-36. PMID: 23121085.

33. Circu ML, Aw TY. Intestinal redox biology and oxidative stress. Semin Cell Dev Biol. 2012;23:729-37. PMID: 22484611.

34. Aw TY. Tissue oxidative stress revisited: significance of ROS and redox signaling. Semin Cell Dev Biol. 2012;23:721. PMID: 22898667.

35. Poyrazoglu Y, Yigit T, Harlak A, Mentes O, Gorgulu S, Uzar Al, Kozak O. Effects of prevention of oxidative and nitrooxidative stress on experimental rat colon anastomosis using acetylcysteine, ebselen and 1400w. Acta Chir Belg. 2011;111:26-31. PMID: 21520784.

36. Teke Z, Bostanci EB, Yenisey C, Kelten EC, Sacar M, Simsek NG, Duzcan SE, Akoglu M. Caffeic acid phenethyl ester prevents detrimental effects of remote ischemiareperfusion injury on healing of colonic anastomosis. J Invest Surg. 2013;26:16-29. PMID: 22646141.

37. Greaves NS, Ashcroft KJ, Baguneid M, Bayat A. Current understanding of molecular and cellular mechanisms in fibroplasia and angiogenesis during acute wound healing. J Dermatol Sci. 2013;72:206-17. PMID: 23958517.

38. Sigalet DL, Wallace LE, Holst JJ, Martin GR, Kaji T, Tanaka H, Sharkey KA. Enteric neural pathways mediate the anti-inflammatory actions of glucagon-like peptide 2. Am J Physiol Gastrointest Liver Physiol. 2007;293:G211-21. PMID: 17395898.

39. Ivory $C P$, Wallace LE, McCafferty DM, Sigalet DL. Interleukin-10-independent anti-inflammatory actions of glucagonlike peptide 2. Am J Physiol Gastrointest Liver Physiol. 2008;295:G1202-10. PMID: 18845573. 
40. Nakame K, Kaji T, Mukai M, Shinyama $\mathrm{S}$, Matsufuji $\mathrm{H}$. The protective and antiinflammatory effects of glucagon-like peptide-2 in an experimental rat model of necrotizing enterocolitis. Peptides. 2016;75:1-7. PMID: 26551873.

\section{Correspondence:}

Beatriz Pinto da Costa

Serviço de Cirurgia A e Clínica Universitária de

Cirurgia III

Hospitais da Universidade de Coimbra

Centro Hospitalar e Universitário de Coimbra

Praceta Mota Pinto, 3000-075 Coimbra, Por-

tugal

Phone: 00351239400417

beatrizpcosta@huc.min-saude.pt

Received: Apr 13, 2017

Review: June 16, 2017

Accepted: July 12, 2017
Conflict of interest: none

Financial source: none

${ }^{1}$ Research performed at Institute of Biophysics, Laboratory of Oncobiology and Hematology, and Institute of Physiology, Faculty of Medicine, Universidade de Coimbra, Portugal. 


\section{Erratum}

Manuscript: Intestinal inflammatory and redox responses to the perioperative administration of teduglutide in rats

Publication: Acta Cir Bras. 2017;32(8):648-661.

DOI: http://dx.doi.org/10.1590/s0102-865020170080000007

On page 652 of the original publication, instead of this Figure 1:
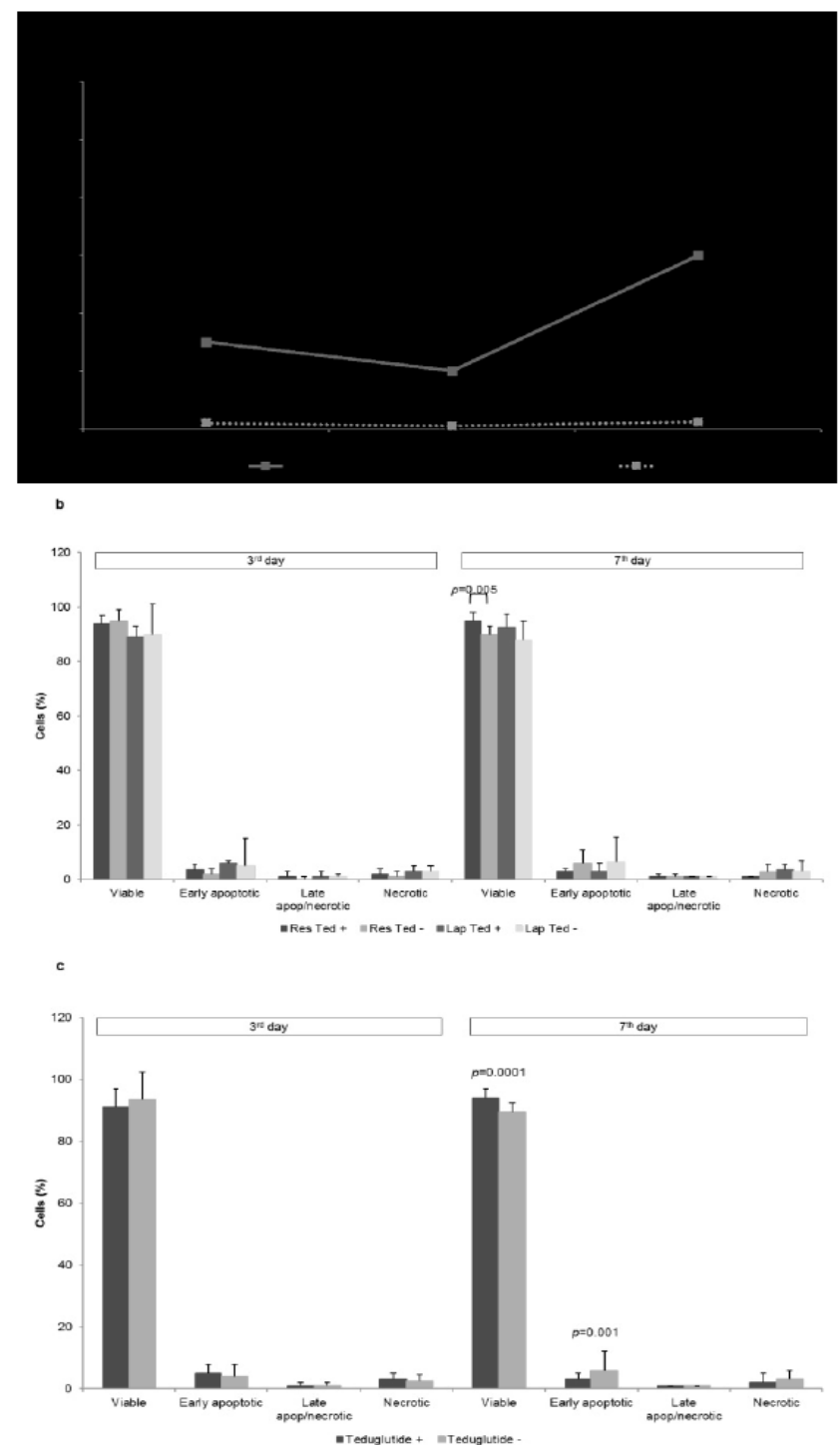

Figure 1 - Analysis of viability and death in cells isolated from rats' ileum, by flow cytometry using double staining with Annexin V/Propidium iodide: at the third and seventh days after ileal resection and anastomosis in animals not submitted to teduglutide treatment (a), in the different groups of study (b) and according teduglutide administration (c).
Consider this Figure 1:
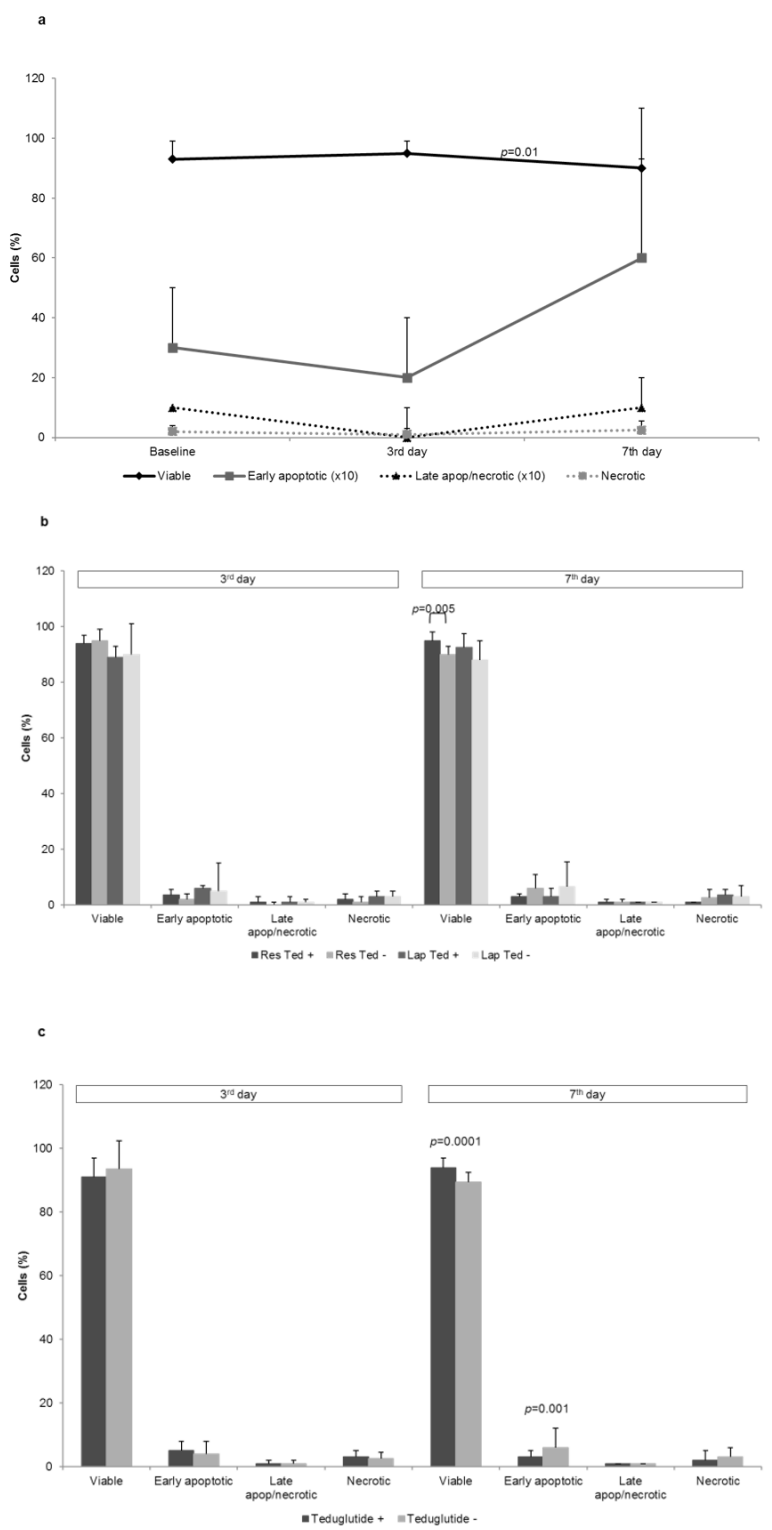

Figure 1 - Analysis of viability and death in cells isolated from rats' ileum, by flow cytometry using double staining with Annexin V/Propidium iodide: at the third and seventh days after ileal resection and anastomosis in animals not submitted to teduglutide treatment (a), in the different groups of study (b) and according teduglutide administration (c). 
On page 653 of the original publication, instead of this Figure 2:
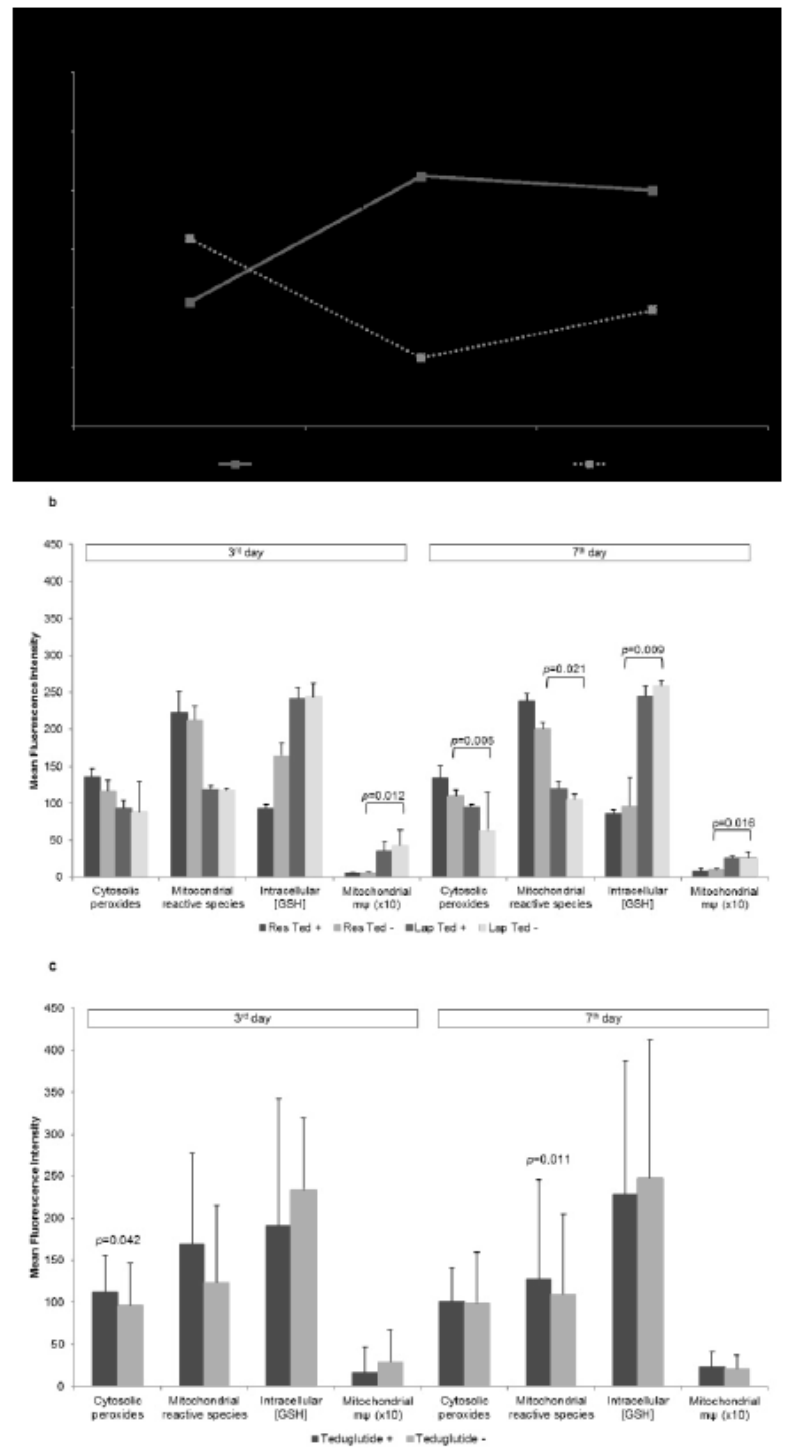

Figure 2 - Oxidative stress evaluation in cells isolated from rats' ileum: at the third and seventh days after ileal resection and anastomosis in animals not submitted to teduglutide treatment (a), in the different groups of study (b) and according teduglutide administration (c). Assessment was performed by flow cytometry using DCFH2DA, DHR123 and JC-1 fluorescent probes and mercury orange to determine cytosolic peroxides level, mitochondrial reactive species generation, mitochondrial membrane potential $(\mathrm{m} \psi)$ and cellular reduced glutathione content ([GSH]), respectively.
Consider this Figure 2:
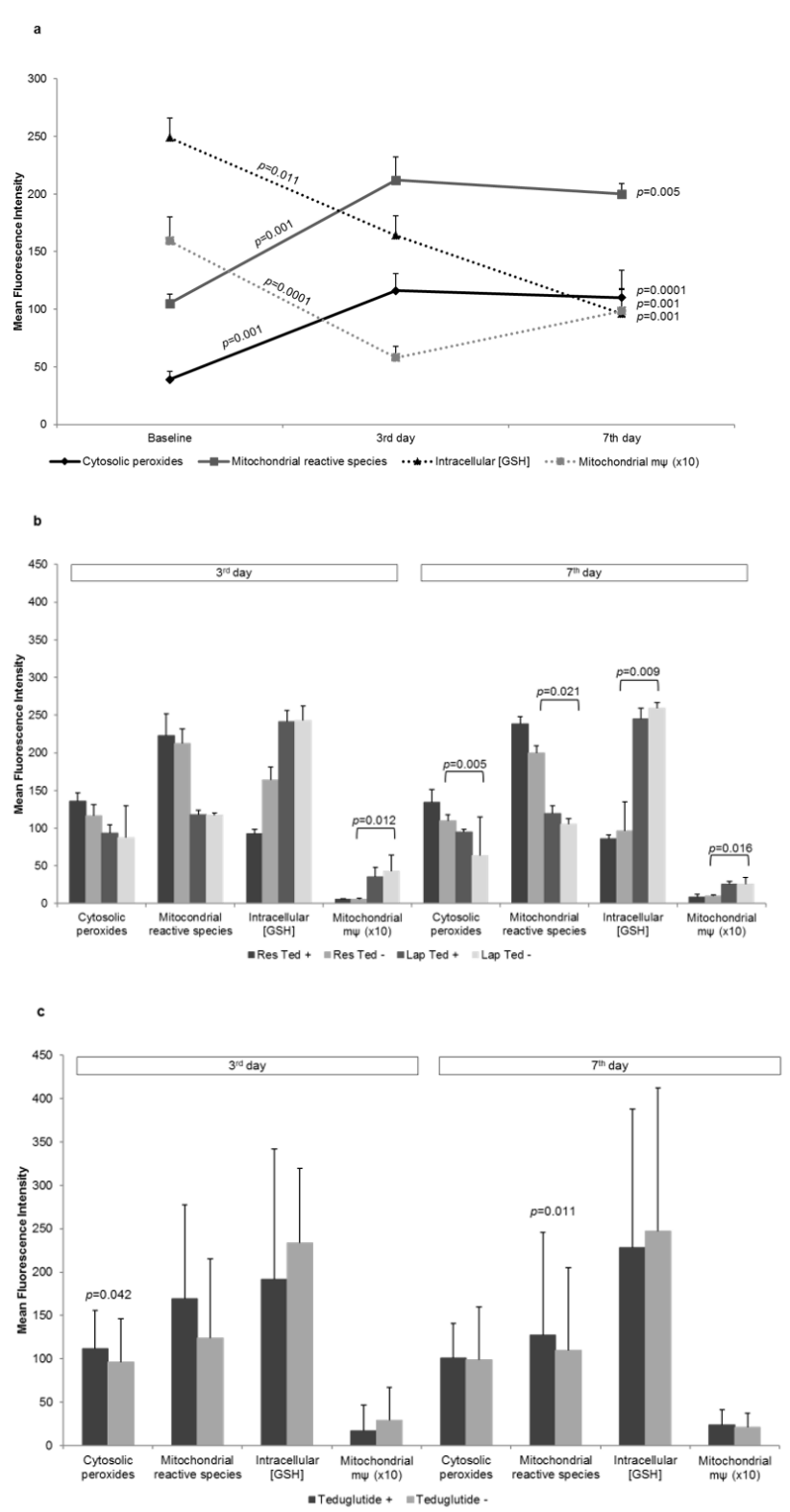

Figure 2 - Oxidative stress evaluation in cells isolated from rats' ileum: at the third and seventh days after ileal resection and anastomosis in animals not submitted to teduglutide treatment (a), in the different groups of study (b) and according teduglutide administration (c). Assessment was performed by flow cytometry using DCFH2DA, DHR123 and JC-1 fluorescent probes and mercury orange to determine cytosolic peroxides level, mitochondrial reactive species generation, mitochondrial membrane potential $(\mathrm{m} \psi)$ and cellular reduced glutathione content ([GSH]), respectively. 
On page 654 of the original publication, instead of this Figure 3:
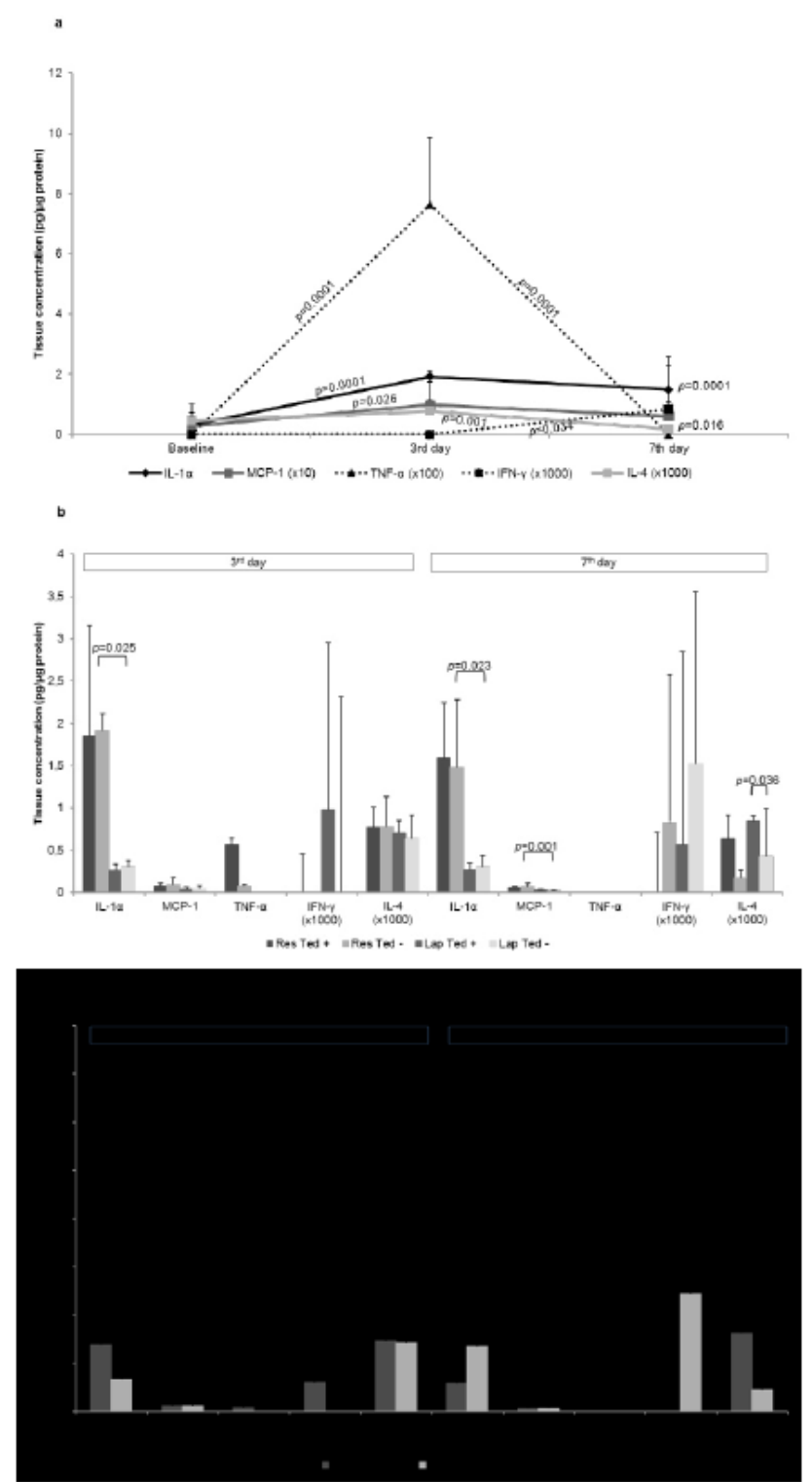

Figure 3 - Analysis of tissue inflammatory response in rats' ileum by flow cytometric multiplexed bead assay: at the third and seventh days after ileal resection and anastomosis in animals not submitted to teduglutide treatment (a), in the different groups of study (b) and according teduglutide administration (c).

\section{Consider this Figure 3:}
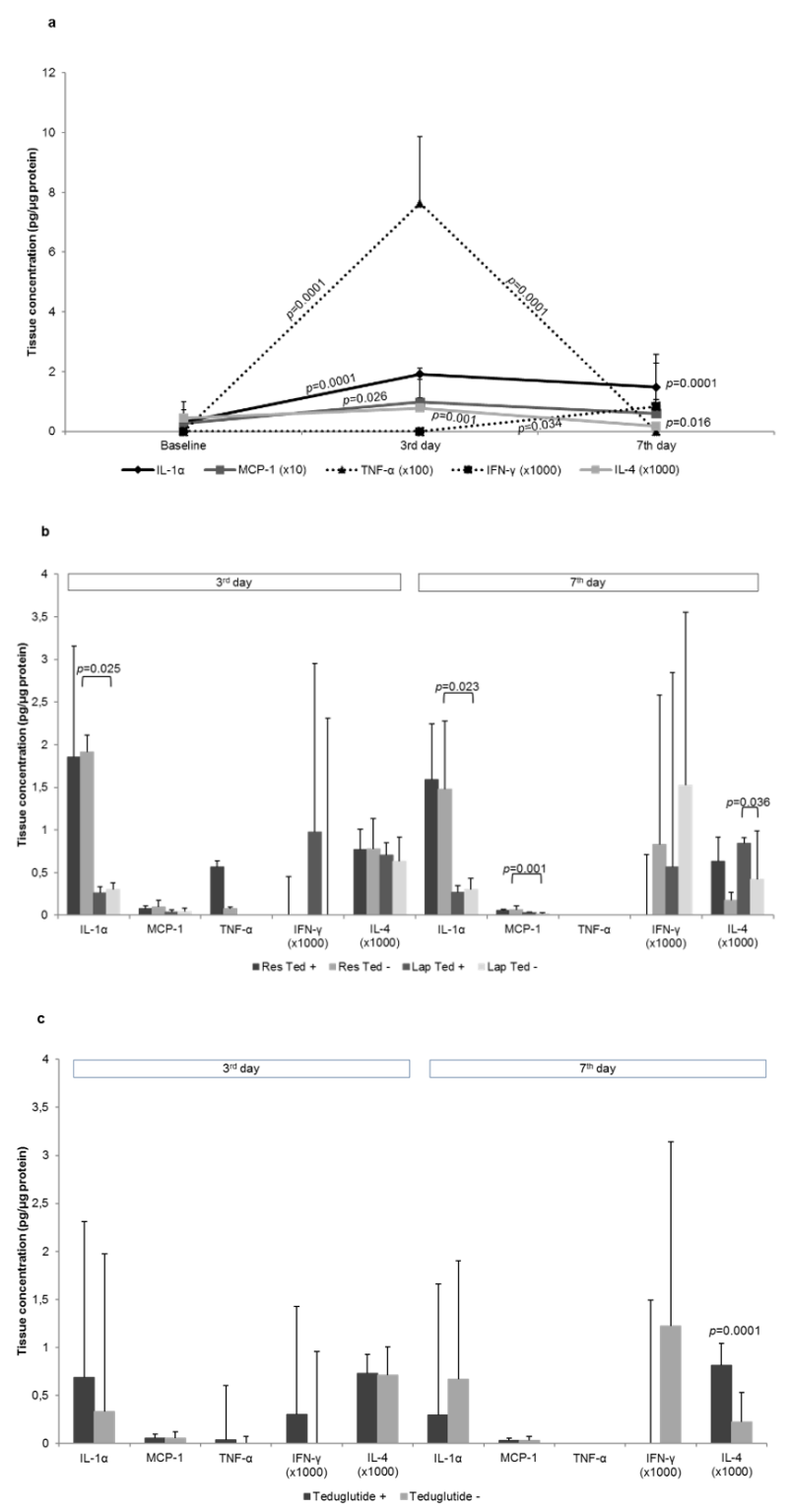

Figure 3 - Analysis of tissue inflammatory response in rats' ileum by flow cytometric multiplexed bead assay: at the third and seventh days after ileal resection and anastomosis in animals not submitted to teduglutide treatment (a), in the different groups of study (b) and according teduglutide administration (c). 
On page 655 of the original publication, instead of this Figure 4:
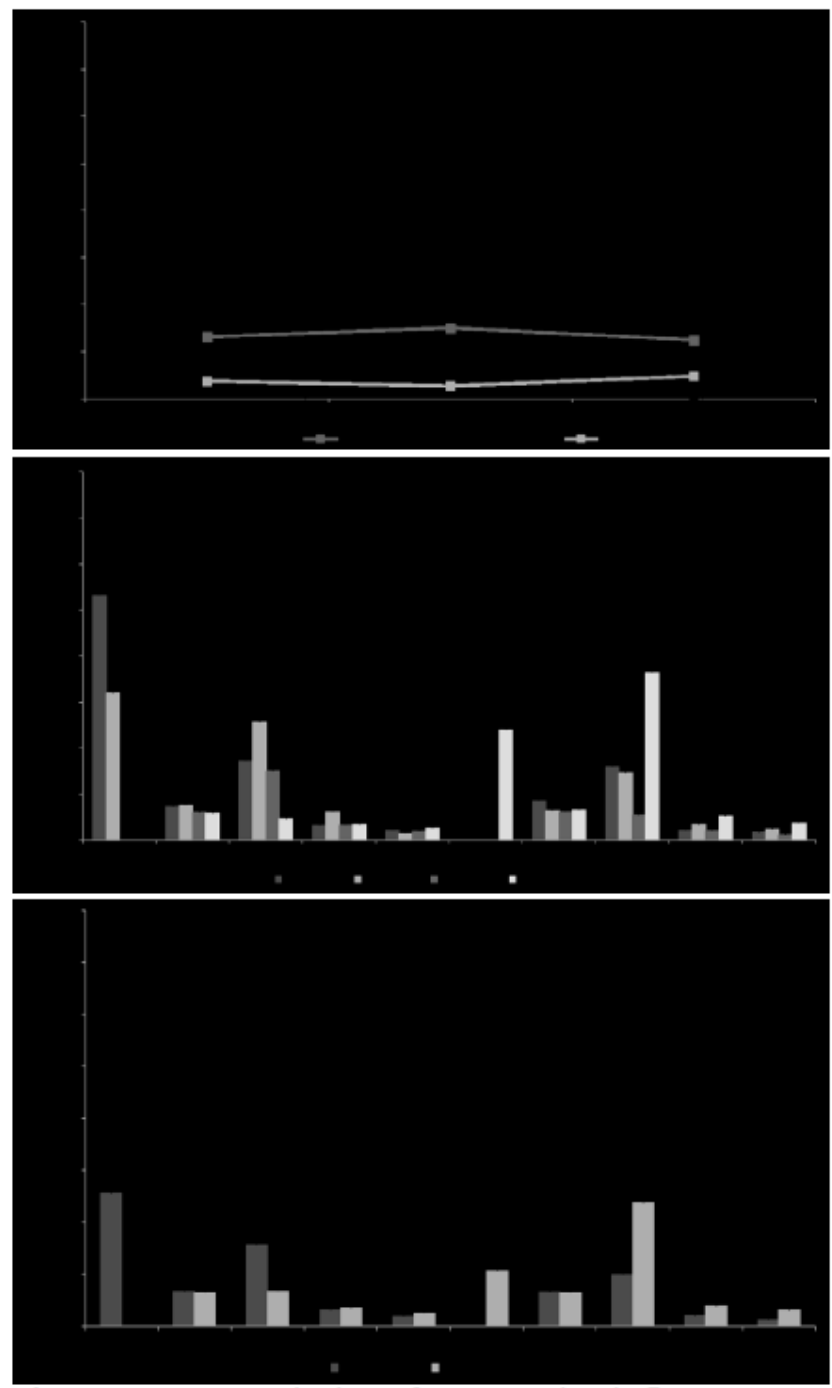

Figure 4 - Analysis of systemic inflammatory response by flow cytometric multiplexed bead assay: at the third and seventh days after ileal resection and anastomosis in animals not submitted to teduglutide treatment (a), in the different groups of study (b) and according teduglutide administration (c).
Consider this Figure 4:
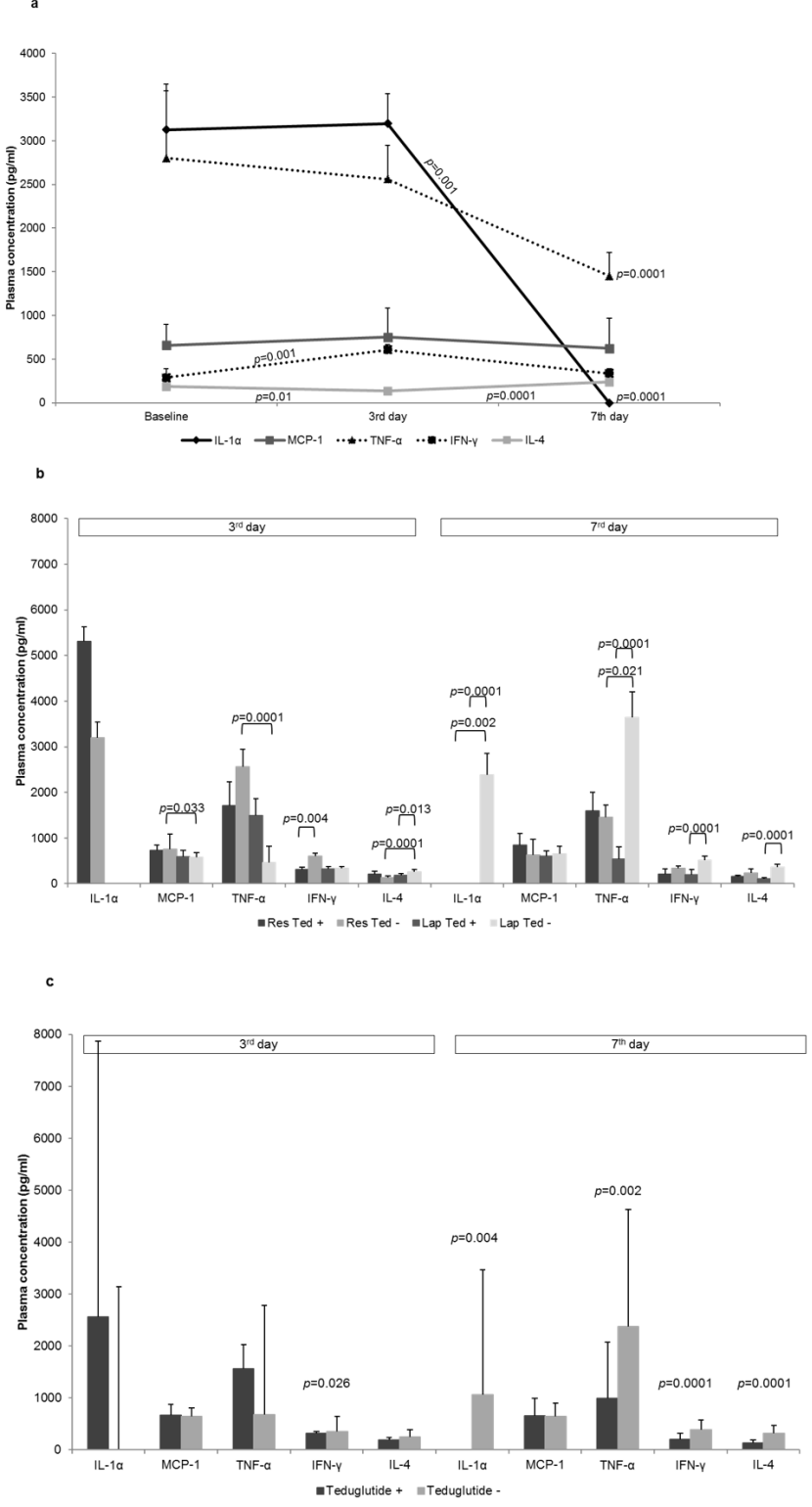

Figure 4 - Analysis of systemic inflammatory response by flow cytometric multiplexed bead assay: at the third and seventh days after ileal resection and anastomosis in animals not submitted to teduglutide treatment (a), in the different groups of study (b) and according teduglutide administration (c). 